\title{
A Contribuição dos Estudos de Gênero para a Compreensão da Geografia do Trabalho: uma pauta para díscussão ${ }^{1}$
}

\author{
The Contribution of the Studies of Gender to the Understanding of Work \\ Geography: a discussion agenda
}

\author{
Susana Maria Veleda da Silva \\ Universidade Federal do Rio Grande \\ susanasilva@furg.br
}

\begin{abstract}
Resumo
A visibilidade das ações das mulheres nas diferentes dimensões impôs para as ciências humanas e sociais os estudos feministas. No sentido de contribuir com os estudos de gênero para a compreensão da geografia do trabalho, utilizo categorias como gênero ou divisão sexual do trabalho a partir do comprometimento político com o feminismo. Assim, sem esgotar os temas, o texto relaciona dialeticamente os seguintes pontos de reflexão e pesquisa: (1) a urgência de estudar os movimentos feministas e a sua contribuição para as ciências humanas e sociais; (2) a necessidade de conhecer a contribuição das geografias feministas; (3) a análise das categorias que auxiliem a geografia do trabalho, dentro do marco conceitual feminista e (4) a imperiosidade de pensar a relação entre feminismo e as geografias do trabalho.
\end{abstract}

Palavras - chaves: geografias feministas; geografias do trabalho; feminismos; gênero; divisão sexual do trabalho.

\begin{abstract}
The visibility given to women's actions in different dimensions has imposed the need for feminist studies in human and social sciences. In an attempt to contribute to the studies of gender aiming at the understanding of work geography, I have used categories, such as gender and sexual division of work, based on political commitment to feminism. Therefore, this paper dialectically works and reflects on the following issues: (1) the urgent need to study feminist movements and their contribution to human and social sciences; (2) the need to know the contribution of feminist geographies; (3) the analysis of categories which help work geography, in a feminist conceptual framework; and (4) the pressing necessity to think about the relation between feminism and work geographies.
\end{abstract}

Keywords: Feminist geographies; Work geographies; Feminism; Gender; Sexual division of work 


\section{Introdução²}

Escrever sobre a contribuição dos estudos de gênero, para a compreensão da geografia do trabalho, constitui-se num objetivo audacioso e transgressor que representa quebra de paradigmas e enfrentamento de preconceitos. Parto do pressuposto de que trabalhar com conceitos feministas nas ciências humanas e sociais é, ao mesmo tempo, assumir um comprometimento político com a transformação do mundo, e assumir uma postura teórico-metodológica empenhada com o desvendamento de categorias e conceitos supostamente neutros e, portanto, significa posicionar-se abertamente.

Sigo Sandra Harding, Virginia Woolf (1882-1941), Alexandra Kolontay (1872-1952), Mary Wollstonecraft (1759-1797), Olimpia de Gouges (1748-1793), Simone de Beauvoir (1908-1986), Elisabeth Badinter, Jutith Butler, Joan Scott, Linda MacDowell, Doreen Massey, Janice Monk, Heleieth Saffioti (1934-2010), Maria Dolors Garcia Ramon e tantas outras pesquisadoras, escritoras e geógrafas que em diferentes tempos e espaços assumem um posicionamento de denuncia das desigualdades e de comprometimento com a busca pela igualdade social.

$\mathrm{O}$ texto corresponde às reflexões construídas ao longo de minha trajetória como professora e pesquisadora, em que incorporo a teoria feminista para estudar o trabalho a partir da perspectiva das relações de gênero, da divisão sexual do trabalho e dos velhos e novos arranjos familiares.

A participação das mulheres no mundo do trabalho remunerado, exercido majoritariamente no espaço público, embora não seja recente, cresceu muito nos últimos quarenta anos. O crescimento da presença das mulheres na população economicamente ativa (PEA) significa mudanças importantes, mas não necessariamente, um equilíbrio de oportunidades entre os sexos no que se refere as condições e as relações de e no trabalho. Condições e relações originadas em uma mentalidade patriarcal ${ }^{3}$ que, fundadas em concepções essencialistas, biológicas e/ou culturais, repartem o trabalho produtivo e reprodutivo entre os sexos a partir das relações sociais de poder: as relações de gênero.

Partindo da concepção de que é necessário utilizar categorias analíticas dentro do marco político e teórico feminista, indico uma pauta de reflexão e pesquisa para aqueles que querem pensar a contribuição dos estudos de gênero para a compreensão da geografia do trabalho e/ou também querem dedicar-se a este enfoque:

- Conhecer os movimentos feministas e a sua contribuição para as ciências humanas e sociais;

- Conhecer a contribuição das geografias feministas 4

- Conhecer categorias que auxiliem a geografia do trabalho, dentro do marco conceitual feminista; e,

- Pensar a relação entre feminismo e as geografias do trabalho.

Para fins de exposição, à concepção apresentada está decomposta em quatro itens que estão dialeticamente relacionados. A seguir, sem esgotar os temas e com o objetivo de provocar reflexões, comento cada item da pauta proposta.

\section{Conhecer os Movimentos Feministas e a Contribuição para as Ciências Humanas e Sociais}

Os movimentos feministas no Brasil acompanharam a busca pelo sufrágio universal do século XIX, o pluralismo dos anos de 1960 e 1970 e influenciaram a produção acadêmica das ciências humanas e sociais. Nestas décadas os movimentos sociais aliaram-se a movimentos políticos mais amplos no combate a ditadura vigente no país (1964 - 1986) e nas reivindicações ligadas a situação das mulheres na política, no mundo do trabalho e na vida cotidiana. Os movimentos das mulheres contribuíram para importantes conquistas, desde aquelas relativas à lutas por aumento de salários e por salários iguais para iguais trabalhos, como aquelas relativas à políticas públicas na esfera da educação, como a construção de creches e na esfera do saneamento básico e da saúde reprodutiva e infantil.

Em 1985 o governo federal criou o Conselho Nacional dos Direitos das Mulheres (CNDM) vinculado ao Ministério da Justiça. Dez anos depois da iniciativa da Organização das Nações Unidas (ONU), em estabelecer o ano de 1975, como Ano Internacional da Mulher e o período de 1975 - 85 como a Década da Mulher. Na década de 1980, o Brasil passa por um processo de redemocratização que culmina com a implementação da Constituição Federal em 1988. A chamada 'constituição cidadã' representa parte dos anseios da sociedade progressista brasileira no que se refere aos direitos humanos fundamentais $\mathrm{e}$ as mulheres - feministas ou não - tiveram ampla participação na elaboração desta carta magna. Tanto os movimentos de mulheres como as constituintes denominadas 'lobby do batom's tiveram uma participação fundamental neste processo.

Nos anos noventa, a luta feminista se dispersa e se institucionaliza a partir da criação de organizações não governamentais que participam de encontros nacionais ou internacionais ampliando o leque de discussões em

\section{Susana Maria Veleda da Silva}


temas como igualdade/diferença, meio ambiente e violência doméstica.

No século XXI, a influência dos movimentos feministas se faz presente institucionalmente, como por exemplo, em 2003, através de medida provisória, o governo brasileiro implementou a Secretaria Especial de Políticas para as Mulheres (SPM). A SPM participa ativamente das políticas públicas relativas às questões das mulheres e, através de editais de fomento, impulsiona a pesquisa feminista e estudos interessados em mostrar as desigualdades de gênero e em propor alternativas práticas e políticas públicas que mitiguem estas desigualdades.

Para a geografia do trabalho é importante conhecer também as parcerias da SPM com a Secretaria de Políticas de Promoção da Igualdade Racial (SEPPIR), o Ministério do Trabalho e Emprego (MTE), o Instituto Brasileiro de Geografia e Estatística (IBGE), o Instituto de Pesquisa Econômica Aplicada (IPEA), o Departamento Intersindical de Estatística e Estudos Socioeconômicos (DIEESE) que, entre outras instituições, fomentam ações em prol do trabalho decente $^{6}$, incluindo a igualdade salarial entre mulheres e homens e de condições para exercer uma profissão.

Estas instituições também contribuem com a coleta e sistematização de dados quantitativos sobre o mundo do trabalho remunerado e não remunerado utilizando as variáveis de sexo, idade, cor da pele, entre outras, contribuindo para o entendimento a partir de generalizações nas diferentes escalas nacionais.

Sinteticamente, posso dizer que a influência dos movimentos feministas na academia inicia no final dos anos de 1960 e toma corpo a partir da década de 1980 e passa pela militância de pesquisadoras(es) que trazem para as ciências humanas e sociais uma renovação de conceitos e paradigmas. A perspectiva feminista aparece com força principalmente nas áreas da Educação, Sociologia, Antropologia, Psicologia, Enfermagem, Literatura e História. Conceitos como trabalho, patriarcado, família e divisão sexual do trabalho são ressignificados a partir das teorias feministas que se embasam na psicanálise, no marxismo, no pós-estruturalismo e a partir dos anos de 1980, os estudos das relações de gênero, os estudos culturais, os estudos pós-coloniais, a teoria queer entre outros. E a geografia brasileira? Como reage aos novos ventos desestabilizadores?

\section{Conhecer a Contribuição das Geografias Feministas}

A incorporação da perspectiva feminista na geografia brasileira é consequência do engajamento político feminista de algumas geógrafas(os) que se inspiram nos estudos de geógrafas(os) e nãogeógrafas(os) europeus e estadunidenses que vêm trabalhando desde a década de 1970, as questões socioespaciais a partir desse enfoque.

Estes primeiros estudos, como os de Zelinsky (1973), de Hanson e Monk (1982) e de Garcia Ramon (1989), objetivam dar visibilidade as mulheres: a metade da população até então ignorada pela geografia.

Em 1982 geógrafas(os) britânicas fundam o Women and Geography Study Group (WGSG) e em 1984 publicam o livro Geography and Gender que define a geografia feminista como:

(...) uma geografia que de forma explícita considera a estrutura de gênero da sociedade e assume um compromisso com o objetivo de atenuar a curto prazo as desigualdades baseadas no gênero e eliminá-las a longo prazo através da transformação / mudança social. (WGSG, 1984, p. 21) 7 .

Geógrafas(os) feministas passam a questionar a cultura ocidental patriarcal e androcêntrica, a ciência e a epistemologia, propondo novos enfoques teóricos e metodológicos (MCDOWELL, 1992). Amplia-se a concepção de que a ciência está contaminada pela visão masculina do mundo, não somente nas teorias, mas nos conceitos e nos métodos de investigação (HARDING, 1993). Argumenta-se que a visão masculina está, também, nas perguntas e na interpretação dos resultados. É preciso denunciar a suposta neutralidade e universalidade da geografia no que se refere ao sexo e ao gênero.

Uma contribuição fundamental para a geografia do trabalho de viés feminista é a produção das geógrafas britânicas Doreen Massey e Linda McDowell. A primeira, dinâmica ativista intelectual que se denomina feminista socialista (ALBET e BENACH, 2012), produziu em sua vasta obra acadêmica e política três textos, que destaco como leituras obrigatórias, para quem quer pesquisar o mundo do trabalho: (1) o Spatial Divisions of Labour de 1984, livro em que traz a concepção feminista para, pioneiramente, mostrar o processo social que começava nos anos de 1980, com a substituição do trabalho masculino de pleno emprego para trabalhos femininos a tempo parcial, tendo como consequência a exploração e a precarização da classe trabalhadora como um todo; (2) o artigo Flexible sexism de 1991, uma critica a David Harvey e Edward Soja que, em suas obras então recém-publicadas (The Condition of Postmodernity, 1989 e Postmodern Geographies, 1989, respectivamente), foram segundo

Susana Maria Veleda da Silva 
Massey profunda e inconscientemente sexistas e desconsideraram os movimentos feministas e suas pautas de reivindicações (ALBET e BENACH, 2012); (3) em 1994, escreve o Space, Place and Gender, em que mostra seu comprometimento com o feminismo como uma relação direta entre sua produção acadêmica e sua vida pessoal.

De Linda McDowell, destaco quatro produções acadêmicas. Nas três primeiras a geógrafa comparte edição e a última é um livro de sua autoria: (1) em 1992, edita Defining Women. Social Institucions and Gender Divisions, o livro apresenta um capítulo dedicado ao trabalho, que se divide em duas partes: Defining work e Gender and wage labour com cinco artigos cada; (2) em 1997, edita Space, Gender, knowledge, como cinco artigos sobre Gendering Work; (3) em 1999, edita A Feminist Glossary of Human Geography com verbetes sobre trabalho e, (4) em 2009 publica o livro Working Bodies. Interactive service employment and workplace identities. Neste livro, McDowell trata de corpos e trabalho e das divisões de gênero do trabalho. Retomando a concepção de que o lugar importa (Geography Matters!) ${ }^{8}$, afirma que existe uma visível divisão espacial do trabalho e, intelectuais feministas também têm demonstrado como os conjuntos de atributos sociais, que são mapeados em corpos generificados, tornam-se fundamentais na construção de divisões de trabalho e em avaliações de cunho hierárquico (2009).

Nos últimos vinte e quatro anos, geógrafas(os) brasileiras(os) realizam estudos pontuais sobre o mundo do trabalho (rural ou urbano) incluindo mulheres e/ou relações de gênero. Cumprindo a função de dar visibilidade as trabalhadoras, Rosa Ester Rossini (1988), pesquisa sobre relações de trabalho das operárias da indústria têxtil em São Paulo e das trabalhadoras do cultivo da cana-de-açúcar e introduz o tema no final de 1980.

Nos anos de 1990, sem abandonar a temática do trabalho, os estudos introduzem novos temas como as questões urbanas, a saúde, os movimentos migratórios e os direitos reprodutivos. Destaco a tese de Sonia Calió (1991), que introduz uma discussão teórica sobre as relações de gênero que não aparecia nos trabalhos anteriores. $\mathrm{O}$ fato de mostrar o papel das mulheres nos espaços urbanos foi um importante passo para a geografia no que tange à perspectiva feminista (VELEDA DA SILVA, 2007).

No século XXI os estudos, antes concentrados na região Sudeste, principalmente no eixo Rio de Janeiro e São Paulo, ampliam-se para outras regiões do país (Sul, Nordeste, Norte e Centro Oeste) e indicam um importante crescimento e uma maior diversificação de temáticas, como: exclusão social, novas tecnologias, assentamentos rurais e sindicatos. As questões socioambientais ligadas à atuação de mulheres em comunidades ou associações é um tema que começa a despontar principalmente na região Norte e Nordeste do país, bem como os temas sobre sexualidades, religiões e masculinidades tratados a partir de uma ótica pós-estruturalista e da teoria queer (SILVA, 2009; ORNAT, 2012) ${ }^{9}$.

Alguns eventos acadêmicos e de associações começam a incorporar temáticas de gênero em eixos, mesas redondas e as diversas comunicações apresentadas de pesquisas na graduação e na pósgraduação demonstram sua importância crescente $^{10}$. Academicamente destaco a produção de dois grupos de pesquisa: o Centro de Estudos de Geografia do Trabalho / CEGeT ${ }^{11}$ e o Grupo de Estudos Territoriais / GETE $^{12}$ sob a coordenação da professora Joseli Maria Silva e suas respectivas revistas eletrônicas: Revista Pegada $^{13}$ e Revista Latino-americana de Geografia e Gênero ${ }^{14}$.

Portanto é cabível afirmar que há mais de vinte anos a geografia brasileira conta com contribuição dos estudos feministas, desde a incorporação de metodologias qualitativas (GARCIA RAMON, 1989) a introdução de conceitos e categorias comprometidos e situados num marco teórico feminista (MASSEY, 1994; McDOWELL, 1999; 2011).

A seguir apresento uma breve discussão sobre algumas possibilidades para se estudar a geografia do trabalho desde uma perspectiva feminista.

\section{Conhecer Categorias que Auxilliem a Geografia do Trabalho dentro do Marco Conceitual Feminista}

Inicialmente insisto numa concepção: metodologias quantitativas e qualitativas não são excludentes e o uso de informações numéricas e/ou discursivas são fundamentais para explicarmos o mundo do trabalho a partir de generalizações e subjetivações. Assim, as categorizações podem ser quantitativas ou qualitativas, mas estão sempre marcadas pelo olhar comprometido do pesquisador(a). As informações quantitativas e/ou qualitativas são fundamentais para entendermos a geografia do trabalho, pois não somente a coleta, mas a análise e as interpretações também passam por caminhos quantitativos e qualitativos.

Os indicadores sociais como medidas, em geral, quantitativas com significado social substantivo, se transformam em recursos metodológicos, empiricamente referidos e informam sobre um aspecto da realidade social ou sobre mudanças que estão se

\section{Susana Maria Veleda da Silva}




\section{A Contribuição dos Estudos de Gênero para a Compreensão da Geografia do Trabalho: uma pauta para discussão}

processando na Tabela 1: Brasil, pessoas de 10 anos ou mais de idade (mil pessoas) por mesma

(JANNUZZI,

2006). E, seguindo

Jannuzzi (2006),

considero que

podem constituir-

se em elementos

de ligação entre os

modelos

explicativos das

teorias feministas

e as evidências empíricas observadas.

Dou alguns

exemplos de

informações

quantitativas ou

indicadores sociais

que nos mostram

situações

de condição de atividade e ocupação por sexo, 2006.

\begin{tabular}{c|cccc}
\hline PEA / PO* & PEA \% & PO \% & $\begin{array}{c}\text { PEA n }^{\circ} \\
\text { absolutos }\end{array}$ & $\begin{array}{c}\text { PO no } \\
\text { absolutos }\end{array}$ \\
\hline Mulheres & 43 & 42 & 42.619 & 37.918 \\
Homens & 56 & 52 & 54.910 & 51.400 \\
\hline
\end{tabular}

* $\mathrm{PEA}=$ População Economicamente Ativa e PO = População Ativa Ocupada. Fonte: IBGE - Pesquisa Nacional por Amostra de Domicílios, 2006. Elaborado por Susana Maria Veleda da Silva.

Tabela 2: Regiões metropolitanas, distribuição da PEA (em \%), entre ocupados e desocupados por sexo 2009.

entre

trabalhadoras e

\begin{tabular}{ccc}
\hline PEA/sexo & Ocupados & Desocupados \\
Mulheres & 86,7 & 13,3 \\
Homens & 91,9 & 8,1 \\
\hline
\end{tabular}

* PEA = População Economicamente Ativa

Fonte: Anuário de Mulheres Brasileiras, 2011. Elaborado por

Susana Maria Veleda da Silva.

trabalhadores em

diferentes escalas geográficas.

Considero que a população economicamente ativa (PEA) é um indicador imprescindível para a geografia do trabalho. No Brasil, em 1995, a participação de mulheres na população economicamente ativa cresceu $63 \%$ em relação a 1985 , enquanto que a participação masculina cresceu $20 \%$ indicando, para o período, um importante ingresso das mulheres no mundo do trabalho remunerado.

Os dados de 2006, mostrados na tabela 1, indicam que no Brasil a participação das mulheres na PEA é um fato, empiricamente observado

constatado. Quais ou que repercussões socioespaciais advêm do crescimento da presença numérica de trabalhadoras?

Se mudamos a escala do nacional para as regiões metropolitanas, em 2009 temos uma maior ocupação masculina e uma maior desocupação feminina. Com um percentual de homens ocupados de $91,9 \%$ e $86,7 \%$ de mulheres ocupadas os desocupados perfazem um percentual de 8,1 e 13,3 respectivamente (tabela 2). Por que as mulheres ainda são o maior numero de desocupados da PEA?

Porém, quando retornamos para a escala nacional, em 2009, verificamos que a distribuição dos ocupados(as) por faixa etária, segundo o sexo apresenta um panorama bem interessante pois, nas faixas etárias de 20 a 39 e de 40 a 59, a porcentagem de mulheres ocupadas é maior do que a dos homens $(51,0 \%$ e $49,2 \%$ na primeira e $36,3 \%$ e $34,3 \%$ na segunda faixa etária (gráfico 1). Qual significado

Gráfico 1: Brasil, distribuição de ocupados (em \%) por faixa etária, segundo sexo, 2009.

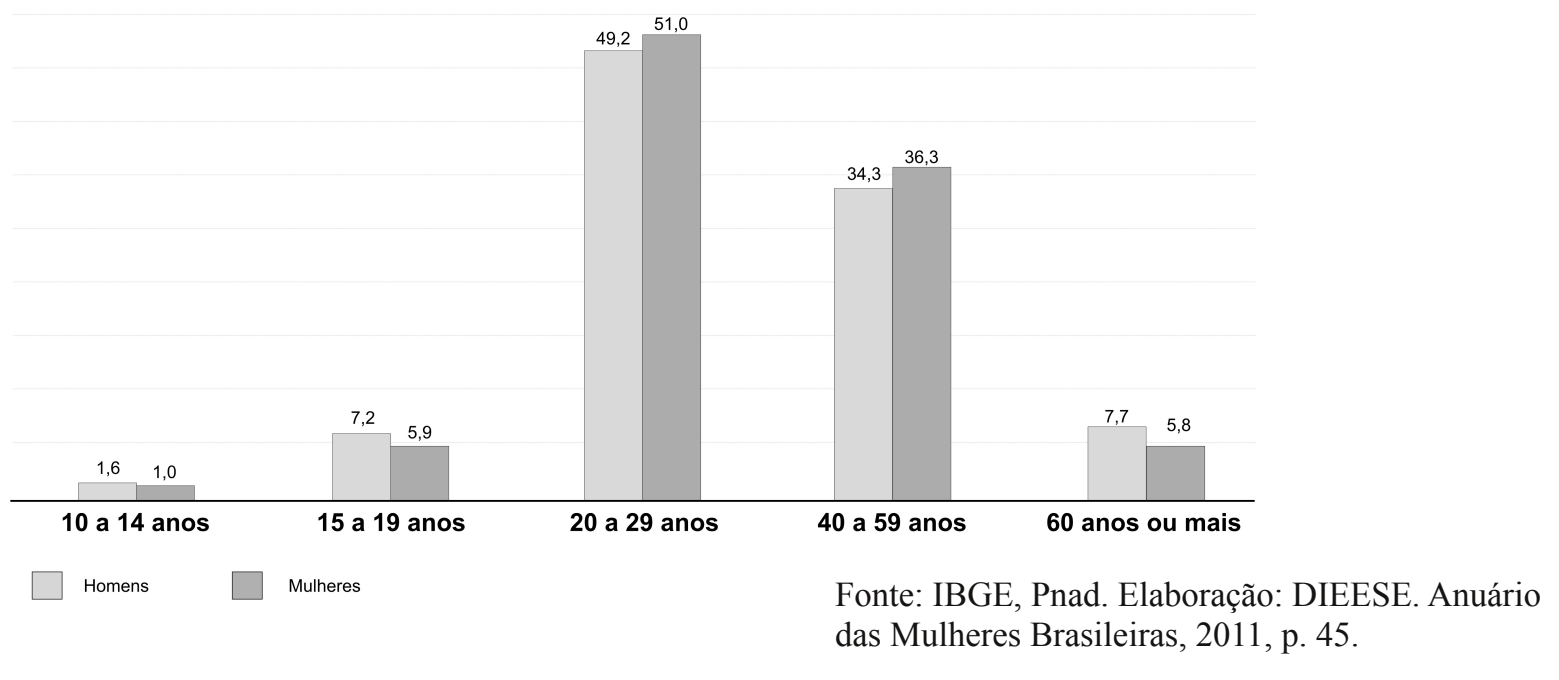

Susana Maria Veleda da Silva 
geográfico destes números? Que sentido espacial podemos lhes dar? Quais as diferenças regionais e de situação de domicílio?

A PEA é um exemplo de indicador necessário, entre tantos outros que, cruzada com a cor da pele, a escolaridade, a faixa etária, a distribuição dos trabalhadores(as) por setores da economia e a faixa salarial, nas diferentes escalas espaciais, permite contextualizar, apontar as desigualdades e explicá-las a partir de categorias qualitativas, construídas a partir das teorias feministas. Ao cruzar, estas e outras variáveis, podemos explicar desigualdades socioeconômicas locais, regionais e nacionais.
Os números da tabela 3 mostram que a desigualdade no mundo do trabalho tem sexo, cor e localização. São as mulheres negras das regiões metropolitanas que contam com o maior percentual de desocupados $(15,5 \%)$, fato que repercute diretamente na remuneração e no orçamento familiar. $\mathrm{O}$ elo entre patriarcado/racismo/capitalismo se consubstancia no espaço relacional ${ }^{15}$.

A disparidade salarial entre mulheres e homens é uma das desigualdades mais vergonhosas no mundo do trabalho remunerado formal. A tabela 4 mostra que em 2010 as trabalhadoras brasileiras ocupadas em empregos formais ganham muito menos que os homens na mesma situação.

Tabela 3: Brasil, distribuição PEA (em \%) por condição de ocupação, segundo cor/raça, sexo e localização do domicílio, 2009.

\begin{tabular}{c|ccccc}
\hline \multirow{2}{*}{ Sexo } & Cor/raça & \multicolumn{2}{c}{ Metropolitano } & \multicolumn{2}{c}{ Não metropolitano } \\
& & Ocupados & Desocupados & Ocupados & Desocupados \\
\cline { 2 - 5 } & Negros(1) & 91,1 & 8,9 & 94,0 & 6,0 \\
\hline \multirow{2}{*}{ Homens } & Não negros (2) & 92,8 & 7,2 & 95,3 & 4,7 \\
\cline { 2 - 6 } & Total (3) & $\mathbf{9 1 , 9}$ & $\mathbf{8 , 1}$ & $\mathbf{9 4 , 6}$ & $\mathbf{5 , 4}$ \\
\cline { 2 - 6 } & Negras (1) & 84,5 & 15,5 & 88,7 & 11,3 \\
\cline { 2 - 6 } & Não negras(2) & 88,7 & 11,3 & 91,5 & 8,5 \\
\hline & Total (3) & $\mathbf{8 6 , 7}$ & $\mathbf{1 3 , 3}$ & $\mathbf{9 0 , 1}$ & $\mathbf{9 , 9}$ \\
\hline
\end{tabular}

* PEA = População Economicamente Ativa

Fonte: IBGE, Pnad. Elaboração: DIEESE. Anuário das Mulheres Brasileiras, 2011, p. 44

Nota: (1) Pretos e pardos; (2) Brancos e amarelos; (3) Inclui indígenas e sem declaração de cor/raça.

Tabela 4: Brasil, remuneração media por sexo (em Reais), dezembro, 2009/ 2010.

\begin{tabular}{c|c|c|c}
\hline Gênero & $\mathbf{2 0 0 9}(\mathbf{R} \mathbf{)})$ & $\mathbf{2 0 1 0}(\mathbf{R} \mathbf{)})$ & $\begin{array}{c}\text { Variação } \\
\text { relativa } \\
\mathbf{( \% )}\end{array}$ \\
\hline Masculino & $1.828,71$ & $1.876,58$ & 2,62 \\
\hline Feminino & $1.514,99$ & $1.553,44$ & 2,54 \\
\hline Total & $1.698,35$ & $1.742,00$ & 2,57 \\
\hline
\end{tabular}

Fonte: RAIS - Decreto n. 76900/1975. Elaboração: CGET/DES/SPPE/MTE. 
Os dados de 2003, para o Brasil, mostram a desigualdade do rendimento-hora de mulheres e homens ocupados relacionadas com os anos de estudo (tabela 5). Num momento em que as mulheres tem maior numero de anos de estudos, são maioria nas universidades e em 2008, as mulheres (51,5\%) ultrapassaram os homens $(48,5 \%)$ em titulação com doutorado (Anuário das Mulheres Brasileiras, 2011), como se explica que o aumento de anos de estudos e da titulação aumenta a desigualdade salarial entre mulheres e homens? Em qual escala geográfica esta desigualdade é mais marcante? Por quê? divisão sexual do trabalho (DST) tem, na força de trabalho feminina, um 'exército de reserva' e a subordinação das mulheres é funcional ao capitalismo. Significa que, nas sociedades patriarcais, a presença ou a ausência das mulheres no mercado de trabalho é fruto do controle da força de trabalho feminino pelos homens (BORDERÍAS, et al., 1984). É Importante lembrar que o 'exército industrial de reserva' afeta o conjunto da classe trabalhadora, mantendo o rebaixamento da remuneração geral, através do maior rebaixamento de quem entrou no mercado de trabalho a partir dos anos de 1970/80: as mulheres ${ }^{16}$.

Tabela 05: Brasil, rendimento-hora da população ocupada (em Reais) por sexo e anos de estudo, 2003.

\begin{tabular}{cccccc}
\hline $\begin{array}{c}\text { Sexo/anos } \\
\text { de estudo }\end{array}$ & Total & Até $\mathbf{4}$ anos & $\mathbf{5}$ a 8 anos & $\mathbf{9}$ a $\mathbf{1 1}$ anos & $\mathbf{1 2}$ anos ou mais \\
\hline Mulheres & 4,00 & 1,90 & 2,40 & 3,40 & 9,80 \\
\hline Homens & 4,80 & 2,40 & 3,40 & 5,00 & 16,20 \\
\hline
\end{tabular}

Fonte: IBGE. Diretoria de pesquisas, Pesquisa Nacional por Amostra de Domicílios, 2003. Elaborado por Susana Maria Veleda da Silva.

Pensar a geografia do trabalho, como se ostrabalhad ores não tivessem sexo e gênero, conduz a uma explicação parcial e equivocada, "pois ambas categorias de sexo são socializadas na ordem patriarcal de gênero" (SAFFIOTI, 2000, p. 71). Para explicar as evidências numéricas das desigualdades temos que lançar mão de categorias feministas. É fato que o crescimento da participação das mulheres no mercado de trabalho ampliou a sua visibilidade nos estudos relativos ao tema e com a categoria gênero. Estudos, antes associados ao trabalho realizado somente no âmbito da produção assalariada e exercido no espaço público abrangem, também, o trabalho doméstico, exercido no espaço privado.

Amplia-se o conceito de trabalho e explica-se a relação família/trabalho através de relações de poder as relações de gênero. Ou seja, a participação das mulheres no mundo do trabalho remunerado expõe sua dupla ou tripla jornada de trabalho e a consequente dificuldade de ascender a postos de trabalho melhor remunerados, bem como expõe a necessidade de se considerar as tarefas domésticas como um trabalho.

Nas décadas de 1960/70 estudos marxistas conceituaram a natureza do trabalho doméstico e suas relações com o modo de produção capitalista, como submetido a 'lógica do capital', assim como a subordinação das mulheres, para algumas feministas, está vinculada à 'lógica do patriarcado'. Para as feministas marxistas a análise do trabalho feminino se dá a partir das dicotomias - patriarcado versus capitalismo e família versus mercado de trabalho. A
O fato é que mulheres e homens entram no mundod o trabalho remunerado em condições diferenciadas e isso acarreta uma desigualdade de oportunidades entre as pessoas no que se refere ao acesso, à permanência, ao tipo de trabalho e a remuneração (BRUSCHINI e RICOLDI, 2008). As condições são produzidas pela DST, uma das formas da divisão social do trabalho, que impõe papéis e funções para mulheres e homens que se expressam no espaço público e no privado, no trabalho e na família.

Segundo Benería (1981) as diferentes formas de machismo se apoiam em uma base econômica definida pela organização da produção e da reprodução social. O domínio dos homens sobre as mulheres desenvolvese, historicamente, pela necessidade de controlar a reprodução e seus vários aspectos e define uma sociedade patriarcal. Assim, no que se refere ao tipo de ocupação, as atividades remuneradas das mulheres são frequentemente uma extensão do trabalho reprodutivo, no âmbito do espaço doméstico e privado, relacionadas com idade, a escolaridade e o tipo de arranjo familiar.

Para as sociedades patriarcais, a remuneração das mulheres é complementar e sua presença é mais importante na reprodução, enquanto que aos homens lhes cabe o papel de provedores da família ${ }^{17}$. Quando as mulheres trabalham como assalariadas, no âmbito de espaço público, estão predominantemente nos setores de serviços e comércio e nas atividades informais, temporárias e precárias ou em setores de atividades formais, mas de baixa remuneração como já nos demonstraram Massey (1984) e Harvey (1992). 
$\mathrm{Na}$ indústria a força de trabalho feminina ainda é absorvida majoritariamente nos setores de alimentos e têxteis, reforçando a tradicional divisão sexual do trabalho e a permanência de estigmas oriundos das relações de gênero. Porém, quando as mulheres assumem empregos considerados 'de homens' ou masculinos, como as engenharias, a construção civil ou mesmo postos de chefia, a associação entre as funções materno - cuidadoras e o estereótipo do gênero feminino são postos em xeque. A maioria das mulheres ainda vive velhos dilemas relacionados com a DST oriunda da sociedade patriarcal, pois são consideradas como 'força de trabalho secundária' $\mathrm{e}$ as únicas responsáveis pelos afazeres domésticos. Observo que a DST também fomenta novos dilemas decorrentes do acesso a profissões consideradas masculinas, como a necessidade de afirmar uma feminilidade ainda oriunda da 'mística feminina'18 e o papel de cuidadoras/responsáveis pelos filhos(as) e a família (VELEDA DA SILVA, 2009).

A divisão sexual do trabalho, como toda relação social, é dinâmica. A passagem do processo de acumulação fordista para a acumulação flexível reestruturou e precarizou o mundo do trabalho. Lembro que:

O capitalismo abriu as portas sim, mas do emprego, pois as mulheres já trabalhavam, havia muito tempo, mais que os homens. A realidade social é contraditória, comportando avanços e retrocessos (SAFFIOTI, 2000, p. 73).

Assim, a incorporação das mulheres no trabalho remunerado, através do emprego, modifica ideias construídas social e culturalmente ao longo do tempo. Portanto as análises do acesso ao trabalho remunerado devem conter fatores que incorporem as mudanças (quantitativas e qualitativas) relacionadas com produção/reprodução, com a incorporação da força de trabalho feminina, com a expansão de novas e velhas formas de trabalho; com os movimentos feministas e sociais; com as políticas públicas de desenvolvimento; com o aumento da escolaridade das mulheres e com as transformações demográficas e culturais.

Aponto que, se por um lado os estudos sobre a temática do trabalho, a partir da perspectiva da geografia de gênero, refletem o número cada vez maior de mulheres incorporando o mundo do trabalho produtivo e assumindo, como provedoras os encargos econômicos da família, estudos indicam que a renda per capita destas famílias é baixa ${ }^{19}$ demonstrando a necessidade de que se pesquise este novo arranjo familiar a partir da geografia econômica, urbana, agrária e/ou da população incorporando a perspectiva feminista.

Por outro lado, esta aumentando o número de homens que assumem tarefas domésticas do trabalho reprodutivo. No Brasil, para o período 2001-2005, o percentual de pessoas de 10 anos ou mais de idade que cuidava de afazeres domésticos indicava que para mulheres era de $89,9 \%$ em 2001 e 90,6\% em 2005, enquanto para os homens, $42,6 \%$ e $51,1 \%$ respectivamente (SOARES e SABOIA, 2007). O que significa este aumento? Como se espacializam? As velhas DST ainda são o suporte de economias agrárias ou urbanas? E as novas DST, calcadas em mentalidades não patriarcais, trarão novas economias? Mais igualitárias e solidárias? Entendo que gênero e DST podem, em conjunto com teoria do patriarcado contribuir sobremaneira para se explicar o mundo do trabalho, seja no espaço urbano ou agrário.

Para finalizar, mas sem esgotar o tema, considero que a geografia do trabalho tem, também, uma interface fundamental com a geografia da população. As variáveis demográficas, como fecundidade, natalidade, mortalidade e migração conformam tipos de arranjos familiares que impõem velhas e novas inserções no mundo do trabalho remunerado e não remunerado. Por exemplo: envelhecimento populacional diferenciado por sexo; mulheres chefes de família; estratégias de divisão do trabalho doméstico entre os membros da família; famílias monoparentais, famílias homossexuais, entre outros arranjos familiares, que resultam em mudanças socioeconômicas e espaciais e talvez em mudanças de mentalidades que caminham para o fim das famílias patriarcais. Mudanças que transformam a geografia do trabalho, pois redefinem acesso, permanência, oportunidades e salários de mulheres e homens. A divisão internacional do trabalho e a própria mobilidade espacial da força de trabalho nacional tem um forte componente de gênero que altera a espacialidade do local de origem e de chegada a partir das relações/condições de trabalho e da transformação das relações familiares, perpetuando ou transformando arranjos familiares.

Assim chego ao último item da pauta proposta que, dialeticamente é a relação que deve perpassar toda a pauta para uma geografia do trabalho.

\section{Pensar a Relação entre Feminismos e as Geografias do Trabalho}

O feminismo, independente das correntes teóricas ou ideológicas, é um projeto político comprometido com as mudanças sociais e orientado para a conquista da igualdade humana. Nesse sentido expõe as 
desigualdades de gênero e mostra como as relações são marcadas por relações desiguais entre mulheres e homens.

As teorias dão sentido e tornam visíveis um conjunto de fenômenos aparentemente heterogêneos e dispersos, assim, a teoria feminista como teoria crítica não é um todo homogêneo nem acumulativo, pois tematiza os diferentes fenômenos através de diferentes paradigmas.

Puleo (1993) sugere que o feminismo radical se consolida através de seis elementos: (1) o uso do conceito de patriarcado como uma regra universal que dá especificidade à agenda militante das mulheres. Entendo que este universal é produzido histórica e geograficamente e, portanto o conceito é relativo e pauta a própria agenda; (2) uma noção ampliada de poder e de política. Considero o poder relacional que (re)produz espaços relacionais (MASSEY, 2004) em uma perspectiva em que o privado também é político; (3) o uso da categoria gênero para rechaçar as atribuições concedidas pelo patriarcado através do processo de naturalização da opressão masculina; (4) uma análise da sexualidade que leva a uma crítica da heterossexualidade compulsória; (5) a denúncia de violência patriarcal incluindo mas não limitado a violência sexual; (6) finalmente, uma sociologia do conhecimento crítica do androcentrismo em todos os campos, incluindo a ciência.

Entendo que a proposta do feminismo radical enquanto teoria e práxis ainda é uma proposta explicativa fundamental para a geografia do trabalho. Não é a única e deve ser enriquecida com as concepções antiessencialistas do pós-estruturalismo que já a muito desmontaram a ideia de um sujeito único e introduziram a concepção das múltiplas identidades.

No Brasil, a perspectiva feminista na geografia ainda é numericamente pouca quando se observa a vasta produção das outras disciplinas ligadas às ciências humanas e sociais. Considero que a resistência dos geógrafos(as) brasileiros em inserir categorias analíticas de matriz feminista pode ter origem num machismo acadêmico ou em um desconhecimento político, histórico, teórico e metodológico sobre as possibilidades que esta perspectiva dá ao estudo do espaço geográfico, particularmente no que se refere aos novos arranjos sócioespaciais decorrentes da relação trabalho e família.

Estou de acordo com a geógrafa Susan Hanson (1992) que, partindo da concepção de que a geografia e o feminismo são forças intelectuais poderosas, considera que não são mundos em conflito, ao contrário, compartilham tradições analíticas como a busca pelo significado da vida cotidiana e a importância do contexto e da diferença. Portanto, devem abrir-se e aprender uma com a outra, não só para transformarem-se mutuamente, mas também para contribuir e oferecer uma concepção mais acabada do mundo.

A geografia possibilita uma boa explicação do mundo, mas esta é mais completa quando considera que o espaço geográfico é constituído de seres humanos que têm sexo e gênero. E enquanto este dado biológico e cultural marcar as pessoas socialmente, economicamente e culturalmente, é fundamental que isto seja levado em conta no momento da investigação geográfica.

Se o mundo não é mais o mesmo no que se refere às relações sociais (na família, na escola, no trabalho...) e fundamentalmente nas relações entre homens e mulheres. Se a vida dos jovens de hoje não se assemelha em nada a vida de suas bisavós/bisavôs, avós/avôs e mesmo de suas mães/pais, é porque uma história de lutas feministas foi construída. Uma história que continua viva e atuante no mundo do trabalho como podemos observar nas fotos 1 e 2 .

Assim entendo que para pesquisar as geografias do trabalho a partir da contribuição dos estudos de gênero é preciso assumir um comprometimento político feminista. Em caso contrário se usará conceitos ou categorias destituídas de sua fundamentação teórica ou como meros instrumentos de captação de recursos para ascensão ou consolidação acadêmica.

Encerro com as palavras de Doreen Massey: "yo quiero feministas en todas partes, en física nuclear, en geomorfologia, en geografia humana, etc. Estudiarlo todo como feministas, no solo estudiar las mujeres y el género" (MASSEY et al, 2009, p. 405). Também quero feministas em todas as partes e na geografia do trabalho!

Foto 1. Grafite em uma porta no distrito de Sant Andreu em Barcelona, março de 2012. Foto da autora.

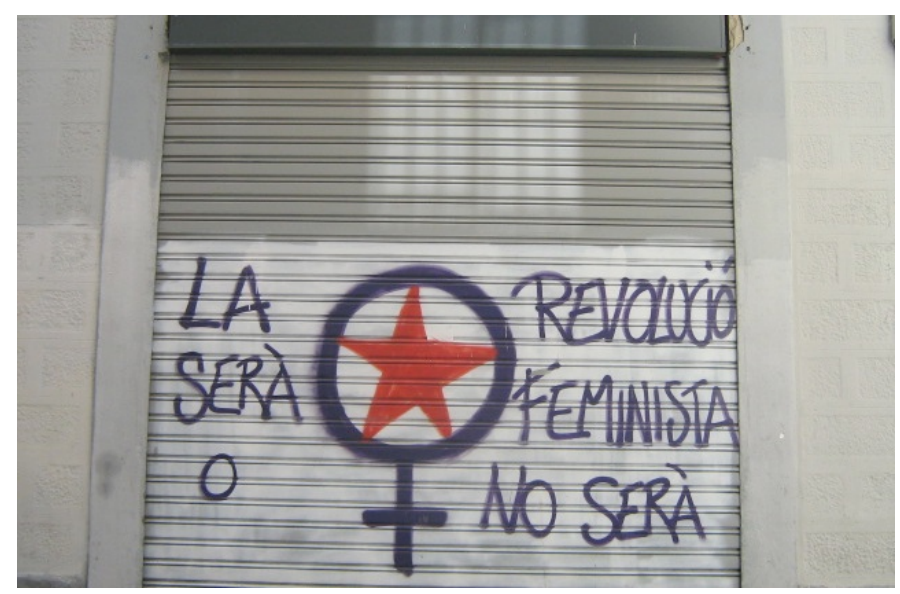


Foto 2: Grafite em uma parede de uma fábrica de pescado, Vigo, maio de 2012. Foto da autora.

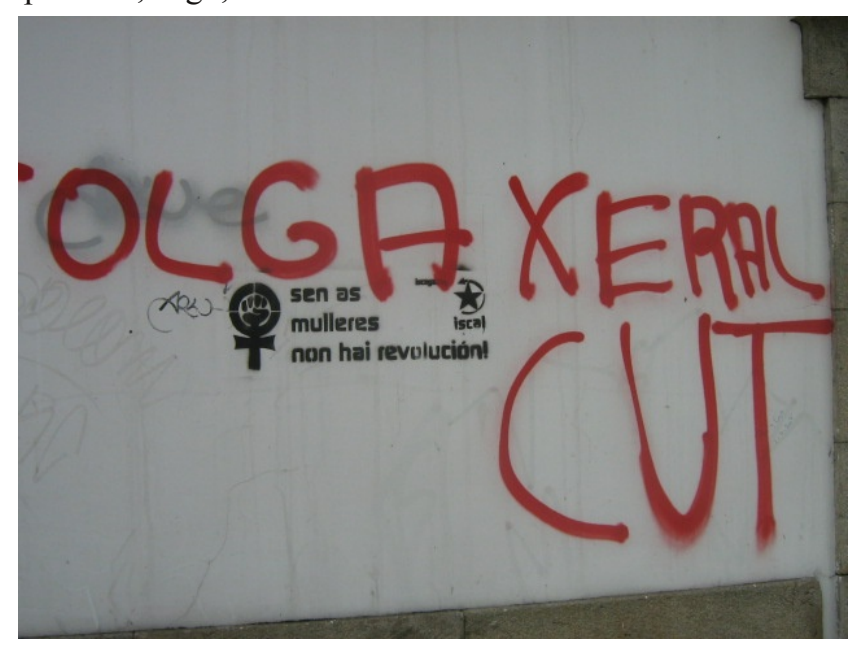

1 O texto apresentado no XVII Encontro Nacional de Geografia (Belo Horizonte, 25/07/2012), é parte da pesquisa de pós-doutorado realizada, em 2012, na Universidad Autónoma de Barcelona, como bolsista da CAPES.

2 Algumas afirmações/reflexões do texto já foram apresentadas no Encontro de Geografía i gènere al mòn: questionant l' hegemonia angloamericana, Barcelona, 2006; no I Seminário Latino-Americano de Geografia e Gênero: espaço, gênero e poder e no Préencontro da Conferência Regional da UGI: conectando diferenças através de fronteiras espaciais, Rio de Janeiro, 2011

3 Sobre mentalidade patriarcal ver o artigo de Heleieth Saffioti (2000): Quem tem medo dos esquemas patriarcais de pensamento?

4 Seguimos Valcárcel (2000, p. 438) ao considerar a geografia feminista e a geografia do gênero como sinônimos.

$5 \quad$ Em 1987 foi instalada a Assembleia Nacional Constituinte com 559 congressistas. A "bancada feminina" era composta de 26 mulheres. Em 2012 a Câmara de Deputados tem 512 parlamentares, destes, 40 são mulheres (ver http://www2.camara.gov.br/deputados/pesquisa ). A participação das mulheres cresceu de apenas 4,65\% em 1987 para 7,8\% em 2012. Em 1987 o Senado Federal contava com 99 Senadores e duas Senadoras e, em 2012, dos 81 senadores, 9 são mulheres. A participação das mulheres no Senado Federal cresceu de $1,98 \%$ em 1987 para 11,1\% em 2012 (ver http://www.senado.gov.br/senadores/).

6 Sobre o conceito de trabalho decente ver Organização Internacional do Trabalho (OIT): http://www.onu.org.br/onu-no-brasil/oit/

7 Tradução livre da autora. Livio
Allen em 1984.

Livro editado por Doreen Massey e John

9 Um panorama não exaustivo da produção acadêmica de estudos de gênero ou feministas na geografia brasileira para o periodo pode ser visto em VELEDA DA SILVA, 2007 e 2009.

10 Ver por exemplo os anais do IX Coloquio Internacional de Geocrítica (2007); X SIMPURB (2007); XII Encontro Latino-americano de Geógrafos (2009); I Seminário Latino-americano de Geografia e Gênero (2011) e o Encontro Nacional de Geógrafos (2012); XII Jornadas do Trabalho (2011).

$$
\begin{array}{ll}
11 & \text { Ver http://www4.fct.unesp.br/ceget/ } \\
12 & \text { Ver http://www.gete.net.br/ } \\
13 & \text { Ver }
\end{array}
$$

http://www4.fct.unesp.br/ceget/pegada.htm

$14 \quad$ Ver

http://www.revistas2.uepg.br/index.php/rlagg.

15 O espaço relacional é entendido e associado como e com as identidades relacionais (MASSEY, 2004). .

16 Refiro-me a passagem do processo de acumulação fordista para a acumulação flexível (HARVEY, 1992).

17 A Organização Internacional do Trabalho (OIT) recomenda a necessidade de superar a visão da mulher como "força de trabalho secundária". Ver http://www.oit.org.br/info/downloadfile.php?fileId=44 2 .

18 Sobre o significado e as consequencias da mística feminina ver o livro homônimo de Betty Friedan (1963). 
19 Ver VELEDA DA SILVA E LESSA CARDOSO (2008). Feminização do mercado de trabalho: as mulheres chefes de família em Rio Grande/Brasil. Ver VELEDA DA SILVA et al. (2011). Mulheres e trabalho: as (i)mobilidades dos estigmas. Projetos financiados pelo Conselho Nacional de Desenvolvimento Científico e Tecnológico (CNPq).

\section{Referências}

ALBET, Abel; BENACH, Nuria. Doreen Massey. Un sentido global del lugar. Barcelona: Icária - Espacios Críticos, 2012.

\section{ANUÁRIO DAS MULHERES BRASILEIRAS} (AMB). São Paulo/ Brasília: Departamento Intersindical de Estatística e Estudos Socioeconômicos (DIEESE) e Secretaria de Políticas para as Mulheres (SPM), 2011.

BENERÍA, Lourdes. Reproducción y división sexual del trabajo. Mientras Tanto, v. 6, p. 47-84, 1981.

BORDERÍAS, Cristina. (et al.). Las Mujeres y el Trabajo - Rupturas Conceptuales. Economía Crítica. Barcelona: FUHEM, 1984.

BRUSCHINI, Cristina; RICOLDI, Arlene. (et al.). Articulação trabalho e família: famílias urbanas de baixa renda e políticas de apoio às trabalhadoras. $n$. 28. São Paulo: FCC/DPE, 2008.

CALIÓ, Sonia. Relações de gênero na cidade: Uma contribuição do pensamento feminista a Geografia Humana. 1991. Tese (Programa de Pós-Graduação em Geografia) - Universidade de São Paulo, São Paulo.

FRIEDAN, Betty. A mística feminista. Petrópolis: Editora Vozes, 1971.

GARCIA RAMON, Maria Dolors. Para no excluir del estudio a la mitad del gènero humano. Un desafio pendiente en Geografia humana. Boletín de la Asociación de Geografos Espanoles, v. 9. p. 27 - 48, 1989.

HANSON, Susan. Geography and feminism: worlds in collision? Annals of the Assocciation of Amercian Geographers, v. 82, n. 4, p. 569 - 586, 1992.

HANSON, Susan; MONK, Janice. On not excluding half of the human in human geography. Professional
Geographer, v. 34, p. 11-23, 1982.

HARDING, Sandra. A instabilidade das categorias analíticas na teoria feminista. Revista de Estudos Feministas, v. 1, n. 1. p. $7-31,1993$.

HARVEY, David. A condição Pós-Moderna. Uma pesquisa sobre as origens da mudança cultural. São Paulo: Loyola, 1992.

JANNUZZI, Paulo. Indicadores Sociais no Brasil. Conceitos, Fontes de Dados e Aplicações. $3^{\mathrm{a}}$ ed. Campinas: Alínea, 2006.

MASSEY, Doreen. Spatial divisions of labour: social structures and the Geography of production. Londres: Macmillan, 1984.

MASSEY, Doreen. Flexible sexism. Environment and Planning D: Sociaty and Space, v. 9, n. 1, p. 3137, 1991.

MASSEY, Doreen. Space, place and gender. Cambridge: Polity Press, 1994.

MASSEY, Doreen. Geographies of Responsibility. Geografiska Annaler, v. 86, n. 1, p. 5-18, 2004.

McDOWELL, Linda. Doing gender: feminism, feminists and research methods in human geography. Transactions of the Institute of British Geographers, v.17, p. 399-416, 1992.

McDOWELL, Linda; PRINGLE, Rosemary (Eds.) Defining Women. Social Institucions and Gender Divisions. Cambridge/Oxford (UK): Polity Press/ The Open University, 1992.

McDOWELL, Linda; SHARP, Joanne. (Eds.) Space, Gender, Knowledge. Feminis Readings. Londres: Arnold, 1997.

McDOWELL, Linda; SHARP, Joanne (Eds.) A Feminist Glossary of Human Geography. Londres: Arnold, 1999.

McDOWELL, Linda. Working Bodies. Interactive service employment and workplace identities. Londres: Wiley-Blackwell, 2009.

ORNAT, Marcio. Espaços Interditos e a Constituição das Identidades Travestis através da Prostituição no Sul do Brasil. Revista Latino-Americana de Geografia e Gênero, v. 3 n.1, p. 54-73, 2012. 
PULEO, Alicia. La Ilustración olvidada. Barcelona: Anthropos, 1993.

ROSSINI, Rosa. Geografia e gênero: a mulher na lavoura canavieira paulista. Tese de Livre Docência, Universidade de São Paulo, 1988.

SAFFIOTI, Heleieth. Quem tem medo dos esquemas patriarcais de pensamento? Dossiê Crítica Marxista, n. 11, p. $71-75,2000$.

SILVA, Joseli Maria. (Org.). Geografias subversivas. Discursos sobre espaço, gênero e sexualidades. Ponta Grossa /PR: Todapalavra, 2009.

SOARES, Cristiane e SABOIA, Ana L. Tempo, trabalho e afazeres domésticos: um estudo com base nos dados da Pesquisa Nacional por Amostra de Domicílios de 2001 e 2005. Textos para discussão, $n$. 21. Rio de Janeiro: IBGE, 2007.

SOJA, Edward. Postmoderm Geographies. The reassertion of space in critical social theory. Londres: Verso, 1989.

VALCARCEL. José O. Los horizontes de la Geografía: teoria da Geografia. Barcelona: Ariel, 2000 .

VELEDA DA SILVA, Susana; LAN, Diana. Geography and gender studies: the situation in Brazil and Argentina. BELGEO, v. 3, p. 371-382, 2007.

VELEDA DA SILVA, Susana; LESSA CARDOSO, Adriana. Feminização do mercado de trabalho: as mulheres chefe de família em Rio Grande/Brasil. (Relatório do projeto com Bolsa Iniciação científica CNPq). Núcleo de Análises Urbanas, (NAU) /FURG, 2008.

VELEDA DA SILVA, Susana (et al). Mulheres e trabalho: as (i)mobilidades dos estigmas. (Relatório do projeto financiado pelo CNPq). Núcleo de Análises Urbanas (NAU) /FURG, 2011.

VELEDA DA SILVA, Susana. A perspectiva feminista na Geografia brasileira. In: SILVA, Joseli Maria (Org.). Geografias subversivas. Discursos sobre espaço, gênero e sexualidades. Ponta Grossa /PR: Todapalavra, 2009, p. 301 - 313.

WOMEN AND GEOGRAPHY STUDY GROUP (WGSG) OF THE IBG. Geography and Gender. An introduction to feminist geography. Londres: Huckchison, 1984.

ZELINSKY, Wilbur. Women in Geography: a brief factual account. Professional Geographer, n. 25, p. 101-106, 1973.
Recebido em 20 de setembro de 2012. Aceito em 2 de fevereiro de 2013. . 